\title{
ANALISIA HIDROGRAF SATUAN DAN WIND ROSE PLOTS PADA DAERAH ALIRAN SUNGAI SEKANAK
}

\author{
Henggar Risa Destania ${ }^{1}$, Achmad Syarifudin ${ }^{2}$ \\ ${ }^{1}$ Engineering Departement, Indo Global Mandiri University, Palembang, Indonesia \\ ${ }^{2}$ Engineering Departement, Bina Darma University, Palembang, Idnonesia \\ Email: 1henggarrisa@uigm.ac.id, 25yarifachmad6080@yahoo.co.id
}

\begin{abstract}
Sekanak watershed is a basins in Palembang which is often affected by flood during the rainy season. The characteristics of the watershed by the impact of changes in land-use by economic and settlement developments. Sekanak watershed has 3 retention ponds which have the function of accommodating temporary discharge during floods. The catchment capacity of the watershed soil type, storage conditions etc. Therefore we need an analysis of the transformation of rainfall data in the watershed into a flow at the watershed control point and an analysis of the transformation of runoff volume (effective rain) into a surface runoff hydrograph (unit hydrograph). Hydrographs measured at a watershed control point are the response or output from rain that falls on a watershed system. The size of the watershed depend on the watershed system. This is closely related in analyzing the availability of water that occurs in the watershed system.
\end{abstract}

Keywords: Hydrograph, river, watershed, sekanak

\section{PENDAHULUAN}

Masalah banjir di Kota Palembang selalu menjadi perhatian utama terutama pada saat musim penghujan. Kota Palembang yang pada dasarnya merupakan kota yang kaya akan air dimana kota ini dilewati oleh salah satu sungai besar yaitu Sungai Musi.

Kondisi topografi Kota Palembang yang sebagian besar terdiri atas dataran rendah dan rawa-rawa mengakibatkan beberapa wilayah di kota ini memerlukan perhatian khusus apabila menjelang musim penghujan.

Perkembangan penduduk dan perekonomian yang begitu pesat membuat keadaan beberapa DAS di Sungai Musi yang memiliki total luas $60.000 \mathrm{~km}^{2}$ yang tersebar di seluruh Kabupaten/Kota ini mengalami dampak yang cukup signifikan terutama terhadap tataguna lahan dan karakteristik DAS (Daerah Aliran Sungai).

Salah satu DAS yang berada di Kota Palembang adalah DAS Sekanak. DAS ini memiliki 3 (tiga) buah kolam retensi yang berfungsi untuk menyimpan sementara debit yang dihasilkan saat banjir. Karakteristik DAS Sekanak pun diduga mengalami perubahanperubahan akibat dampak curah hujan yang begitu besar, kapasitas tampungan DAS, jenis tanah dan faktor lainnya.

Dalam analisis hidrologi, data aliran di titik kontrol suatu DAS sangat diperlukan. Akan tetapi pada umumnya data aliran (debit) di titik control tidak tersedia sedangkan data hujan yang tersedia cukup panjang (biasanya harian). Oleh karena itu diperlukan analisis 
transformasi data hujan di DAS menjadi aliran di titik kontrol DAS dan analisis transformasi volume limpasan (hujan efektif) menjadi hidrograf limpasan permukaan (hidrograf satuan). Hidrograf yang terukur di suatu titik kontrol DAS merupakan respon atau keluaran dari hujan yang jatuh di suatu sistem DAS. Besar respon DAS akan sangat bergantung dari sistem DASnya. Hal ini erat kaitannya dalam menganalisis ketersediaan air yang terjadi di sistem DAS.

Besaran $\Phi$-indeks untuk beberapa kasus banjir yang terjadi di DAS Sekanak mendapatkan gambaran terhadap karakteristik DAS Sekanak dan respon DAS Sekanak terhadap perubahan curah hujan dan tata guna lahan serta memberikan rekomendasi bagi pemerintah sebagai upaya antisipasi dan pengendalian risiko yang ditimbulkan oleh banjir DAS Sekanak. Bagi masyarakat umum, penelitian ini juga memberi wawasan dalam sistem pengendalian banjir yang ada dan menjadi sarana pembelajaran dalam penelitian selanjutnya.

\section{METODE}

\subsection{Tinjauan Pustaka}

Berdasarkan siklus (daur) hidrologi, air yang berada di bumi baik langsung maupun tidak langsung merupakan dari air hujan (presipitasi). Hujan merupakan faktor utama dalam pengendalian siklus hidrologi dalam suatu wilayah seperti kelembapan tanah, proses infiltrasi, dan debit aliran. Tingkat curah hujan bervariasi secara geografis dari waktu ke waktu

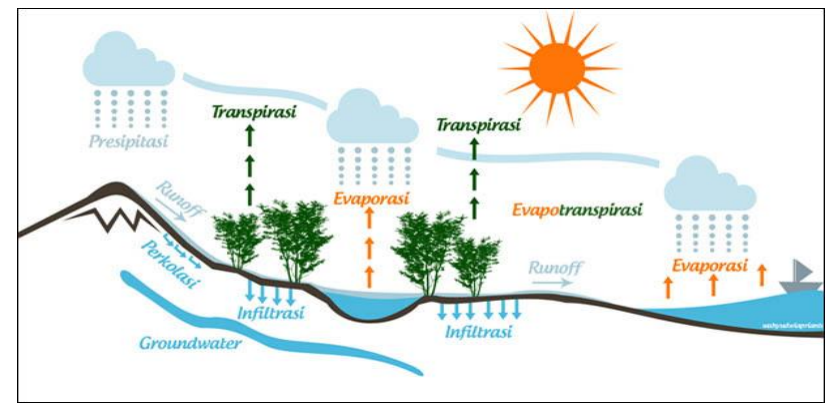

Gambar 1 Siklus Hidrologi

Daerah Aliran Sungai (DAS) merupakan daerah di permukaan bumi yang dibatasi oleh puncak-puncak pegunungan dimana air hujan yang jatuh di daerah tersebut akan mengalir menuju sungai utama melalui titik output. Sebagai suatu sistem hidrologi, DAS merupakan daerah cekungan yang dibatasi oleh topografi yang tinggi berupa punggungan bukit yang berfungsi menerima dan menyimpan air hujan yang jatuh di atasnya yang kemudian di alirkan baik secara langsung maupun tidak langsung ke aliran sungai yang bermuara ke sungai atau laut [2];[3].

Kondisi DAS dikatakan tidak dalam kondisi yang baik apabila terdapat gangguan ekosistem didalamnya [4];[5]. Ekosistem yang dimaksud adalah berasal dari penghuni suatu DAS yaitu manusia. Hal ini mengakibatkan fungsi DAS menjadi terganggu dan berdampak pada sistem hidrologisnya. Sehingga apabila masuk musim hujan akan 
(Civil Engineeering, Elektrical Engineeering and Industrial Engineering)

Vol. 17, No : 2, Oktober 2020, p-ISSN:1907-5243, e-ISSN: 2655-8416

menghasilkan debit yang melimpah dan saat musim kering menjadi sangat minim akibat kerusakan yang terjadi di daerah tangkapan, dan penyimpanan air.

Bentuk dan ukuran dari DAS ditentukan oleh topografi dataran seperti yang ditunjukkan pada gambar 2 berikut.

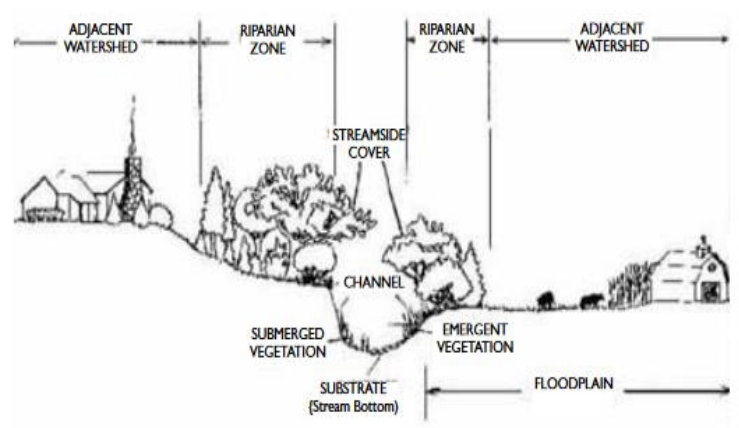

Gambar 2 Konsep Daerah Aliran Sungai (DAS)

Hidrograf satuan suatu daerah aliran sungai dapat diperoleh dengan suatu analisis hitungan berdasarkan data hujan jam-jaman dan hidrograf (debit rerata jam-jaman) akibat kejadian hujan tercatat [6]. Hidrograf satuan merupakan hidrograf khas dari suatu DAS tertentu. Hidrograf satuan merupakan hidrograf khas dari suatu DAS yang mempunyai limpasan langsung oleh hujan efektif yang terjadi merata di setiap luasan DAS dengan intensitas tetap dalam satu satuan waktu yang ditetapkan. Konsep HS ditemukan pertama kali oleh Sherman yang digunakan untuk perkiraan banjir yang terjadi akibat hujan dengan kedalaman dan agihan (distribusi) tertentu [7].

Terdapat dua anggapan pokok dalam teori hidrograf satuan (HS) yaitu; hujan merata di seluruh DAS dan intensitas hujan tetap. Selain itu teori HS juga didasarkan pada 3 landasan pemikiran yaitu sistem DAS linier, time invariant dan waktu dasar (waktu mulai dan akhir hidrograf limpasan tetap). Konsep HS diilustrasikan pada gambar 3 berikut.

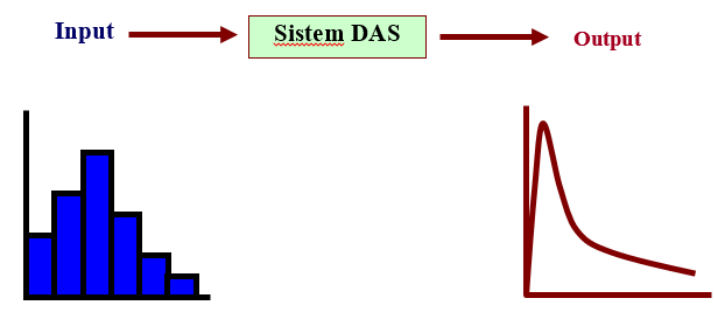

Gambar 3 Alih ragam limpasan sistem DAS

\subsection{Metodelogi Penelitian}


Lokasi penelitian direncanakan berada di DAS Sekanak Provinsi Sumatera Selatan. Sungai Sekanak ini terletak di wilayah administrasi kecamatan Ilir Timur I yang sebagian besar merupakan kawasan dengan permukiman padat yang sering mengalami banjir saat musim penghujan. Berikut data yang diperlukan dalam penelitian ini adalah :

1. Data Primer

Data primer yang digunakan merupakan data yang didapat melalui survei langsung berupa foto-foto dokumentasi ke lokasi penelitian dan wawancara kepada masyarakat terhadap perilaku daerah aliran sungai yang menyebabkan terjadinya banjir.

2. Data Sekunder

Beberapa data sekunder yang digunakan adalah:

a. Data primer berupa data curah hujan otomatis yang berada di stasiun DAS Sekanak

b. Data topografi dan data hujan wilayah

c. Data ketinggian muka air yang terekam pada AWLR (Automatic Water Level Recorder) di DAS Sekanak

d. Data ARR (Automatic Rainfall Recorder) dengan pos stasiun yang digunakan adalah stasiun hujan Kenten, Talang Betutu, Plaju dan Tanjung Batu dari Badan Meterologi dan Geofisika Palembang

e. Data Karakteristik DAS Sekanak yang di dapat dari Bappeda Kota Palembang

Metode yang digunakan dalam penelitian ini adalah:

1. Metode Analisis Loss Method/Abstraction

a. Koefisien Limpasan (Runoff Coefficients) dapat digunakan untuk menghitung besarnya hujan efektif/volume hujan yang menjadi limpasan.

$$
C=\frac{t_{l l}}{\sum_{m=1}^{M} R_{m}}
$$

b. Perhitungan nilai $\Phi$-indeks untuk setiap kasus banjir dan $\Phi$-indeks rerata

$$
t_{l l}=\sum_{m=1}^{M}\left(R_{m}-\Phi \Delta t\right)
$$

c. Perhitungan nilai $\mathrm{CN}$ untuk setiap kasus banjir dan $\mathrm{CN}$ rerata

$$
\sum P_{e}=\frac{\left(\sum P-I_{a}\right)^{2}}{\sum P-I_{a}+S} \quad S=\left(\frac{1000}{C N}-10\right) \times 25.4(\mathrm{~mm})
$$


(Civil Engineeering, Elektrical Engineeering and Industrial Engineering)

Vol. 17, No : 2, Oktober 2020, p-ISSN:1907-5243, e-ISSN: 2655-8416
d. Hidrograf satuan
Beberapa metode yang dapat digunakan untuk menurunkan hidrograf satuan seperti metode polynomial dan metode Collins.

2. Metode analisa WR plot

Metode ini bertujuan untuk mengilustrasikan data statistik dan meteorologi hujan seperti durasi, intensitas dan arah angin dalam bentuk grafik windrose dan plot.

3. Metode Hidrograf Satuan Sintetik

Hidrograf satuan yang diperoleh dari data karakteristik DAS disebut hidrograf satuan sintetik yaitu dengan menghitung unsur-unsur pokok hidrograf satuan (Qp, Tp dan Tb) sebagai fungsi karakteristik DAS.
a. Metode Gama I
b. Metode Nakayasu
c. Metode SCS

\section{HASIL DAN PEMBAHASAN}

Data curah hujan yang digunakan dalam penelitian ini diperoleh dari data kejadian banjir pada tanggal 13 November 2018, 15 Oktober 2018, 05 Desember 2018 dan dengan curah hujan maksimum $87 \mathrm{~mm}$ selama 4 jam dari data yang tersedia selama 9 tahun di Stasiun Hujan Kenten.

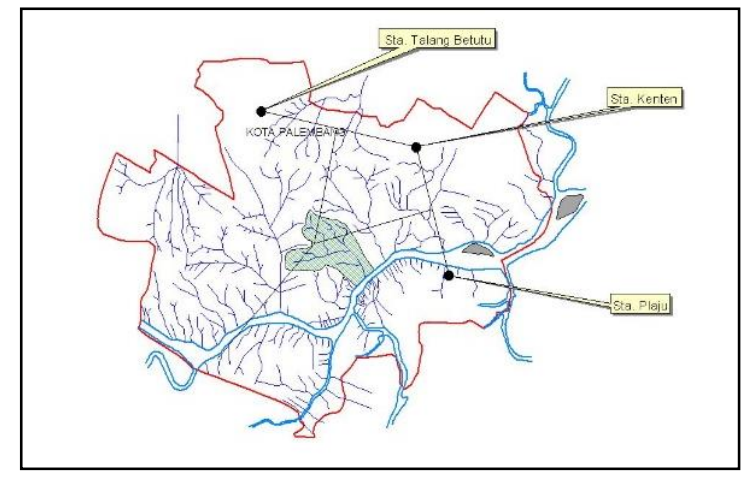

Gambar 4 Lokasi stasiun curah hujan

Data curah hujan dari 3 stasiun hujan tersebut merupakan data curah hujan di lokasi penelitian yang digunakan sebagai data masukan untuk curah hujan rata-rata maksimum di DAS Sekanak. Untuk menentukan curah hujan tersebut maka digunakan metode rata-rata Poligon Thiessen. 
Jurnal TEKNO

(Civil Engineeering, Elektrical Engineeering and Industrial Engineering)

Vol. 17, No : 2, Oktober 2020 , p-ISSN:1907-5243, e-ISSN: 2655-8416

Tabel 1 Perhitungan curah hujan rata-rata maksimum

\begin{tabular}{|c|c|c|c|c|}
\hline Tahun & Kenten & Plaju & $\begin{array}{c}\text { Tlg. } \\
\text { Betutu }\end{array}$ & Rata-rata \\
\hline 2008 & 105 & 134 & 65 & 101 \\
\hline 2009 & 115 & 87 & 111 & 104 \\
\hline 2010 & 87 & 125 & 82 & 98 \\
\hline 2011 & 99 & 146 & 82 & 109 \\
\hline 2012 & 110 & 72 & 115 & 99 \\
\hline 2013 & 215 & 65 & 172 & 150,6667 \\
\hline 2014 & 114 & 34 & 83 & 77 \\
\hline 2015 & 96 & 98 & 119 & 104,3333 \\
\hline 2016 & 113.8 & 140 & 127 & 133,5 \\
\hline 2017 & 121 & 146 & 143 & 136,6667 \\
\hline 2018 & 83.6 & 135 & 163 & 149 \\
\hline
\end{tabular}

Persentase kejadian hujan dihitung selama tahun 2016 dan tahun 2017 dengan asumsi jumlah kejadian hujan dalam mm 1 satuan setiap 2 menit nya. Persentase kejadian hujan ditunjukkan dalam pembagian interval $0-10 \mathrm{~mm} / \mathrm{hr}, 10-20 \mathrm{~mm} / \mathrm{hr}, 20-30 \mathrm{~mm} / \mathrm{hr}, 30$ - $40 \mathrm{~mm} / \mathrm{hr}, 40-50 \mathrm{~mm} / \mathrm{hr}$, dan $50-60 \mathrm{~mm} / \mathrm{hr}$. Pola kejadian hujan tersebut ditampilkan dalam gambar berikut.

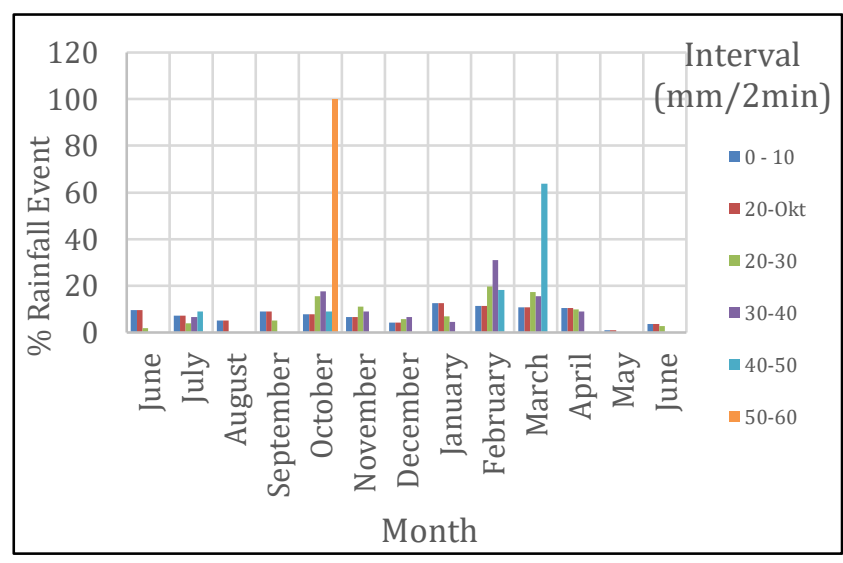

Gambar 5 Persentase Kejadian Hujan sepanjang tahun 2016 - 2017

Berdasarkan Gambar 5 dapat disimpulkan bahwa kejadian hujan maksimum terjadi pada bulan Oktober 2016 dengan interval $50-60 \mathrm{~mm} / \mathrm{hr}$ dengan persentase maksimal dengan nilai $100 \%$. Hal ini sesuai dengan probabilitas kejadian banjir yang terjadi selama bulan Oktober. 


\section{Jurnal TEKNO}

(Civil Engineeering, Elektrical Engineeering and Industrial Engineering)

Vol. 17, No : 2, Oktober 2020, p-ISSN:1907-5243, e-ISSN: 2655-8416

Tabel 2 Presentase Kejadian Hujan Maksimum untuk tiap Interval

\begin{tabular}{|l|c|c|c|}
\hline No. & Interval & Bulan & $\begin{array}{c}\% \\
\text { Kejadian }\end{array}$ \\
\hline 1 & $0-10 \mathrm{~mm} / \mathrm{hr}$ & Februari 2017 & 12,52 \\
\hline 2 & $10-20 \mathrm{~mm} / \mathrm{hr}$ & Februari 2017 & 19,09 \\
\hline 3 & $20-30 \mathrm{~mm} / \mathrm{hr}$ & Februari 2017 & 19,65 \\
\hline 4 & $30-40 \mathrm{~mm} / \mathrm{hr}$ & Februari 2017 & 31,11 \\
\hline 5 & $40-50 \mathrm{~mm} / \mathrm{hr}$ & Maret 2017 & 63,64 \\
\hline 6 & $50-60 \mathrm{~mm} / \mathrm{hr}$ & Oktober 2016 & 100 \\
\hline
\end{tabular}

\section{A. Analisa data dengan Wind Rose Plot}

WR Plot menunjukkan grafik sebaran data meteorologi hujan dalam bentuk wind rose dan plot. Tabel 3 berikut menunjukkan input analisis data WR Plot.

Tabel 3 Input data analisa WR Plot

\begin{tabular}{|c|c|c|c|c|c|r|}
\hline Tahun & Bulan & Tanggal & Jam & $\begin{array}{c}\text { Lama } \\
\text { Hujan } \\
\text { (jam ke-) }\end{array}$ & $\begin{array}{c}\text { Kedalaman } \\
(\mathrm{mm})\end{array}$ & $\begin{array}{c}\text { Lama } \\
\text { Hujan }{ }^{\circ} \text { ) }\end{array}$ \\
\hline 2008 & 1 & 4 & 20 & 13 & 84 & 360 \\
\hline 2009 & 1 & 13 & 21 & 2 & 56 & 90 \\
\hline 2010 & 1 & 25 & 22 & 1 & 52 & 45 \\
\hline 2011 & 2 & 15 & 23 & 2 & 103 & 90 \\
\hline 2012 & 2 & 17 & 24 & 6 & 54 & 270 \\
\hline 2013 & 2 & 24 & 1 & 5 & 59 & 225 \\
\hline 2014 & 3 & 7 & 2 & 3 & 100 & 135 \\
\hline 2015 & 3 & 15 & 3 & 3 & 65 & 135 \\
\hline 2016 & 3 & 20 & 4 & 5 & 53 & 225 \\
\hline 2017 & 3 & 28 & 5 & 3 & 69 & 135 \\
\hline 2018 & 4 & 5 & 6 & 8 & 121 & 360 \\
\hline
\end{tabular}
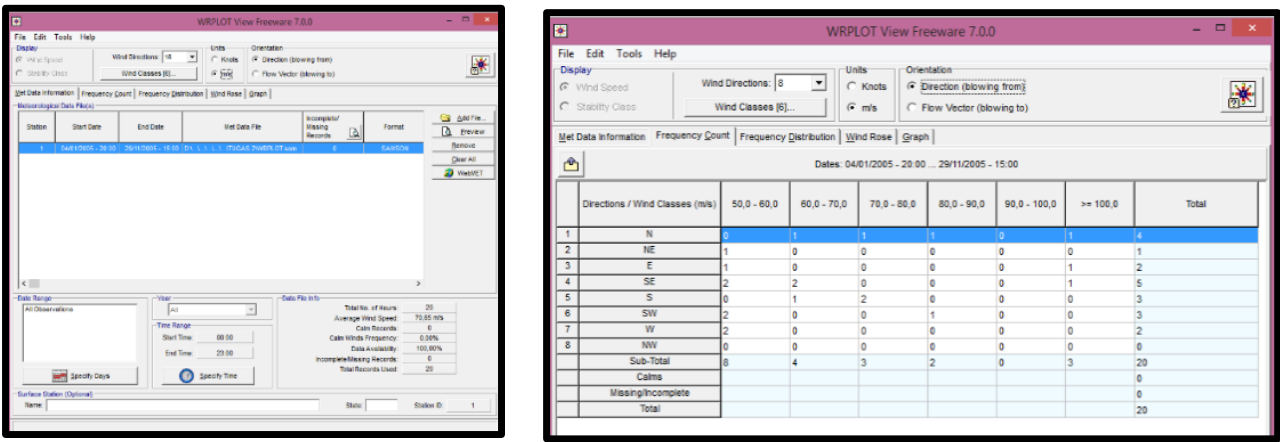

Gambar 6 Input data WR Plot 


\section{Jurnal TEKNO}

(Civil Engineeering, Elektrical Engineeering and Industrial Engineering)

Vol. 17, No : 2, Oktober 2020 , p-ISSN:1907-5243, e-ISSN: 2655-8416

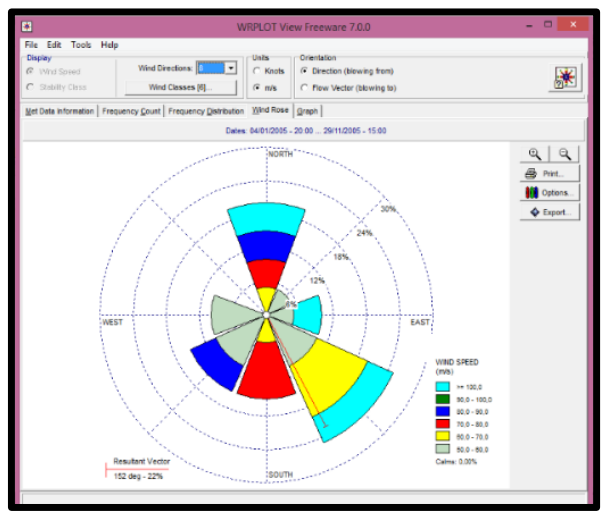

Gambar 7 Tampilan windrose

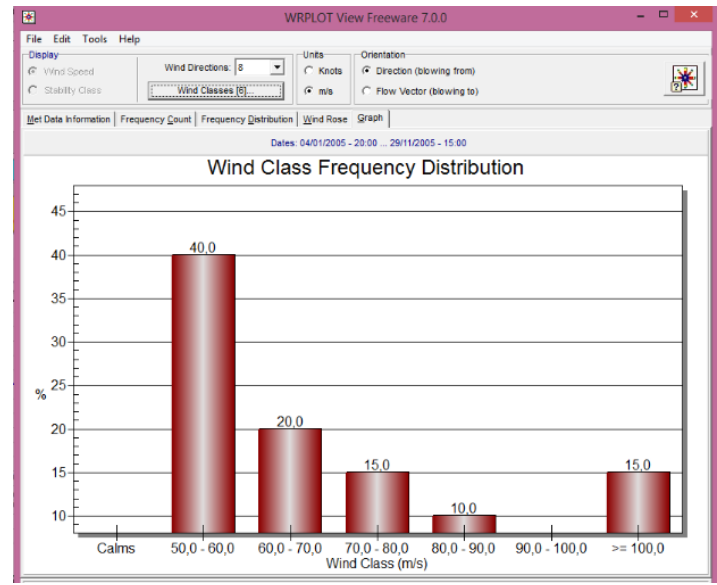

Gambar 8 Diagram distribusi kecepatan angin

B. Hidrograf Satuan

Perhitungan analisis hidrograf di DAS Sekanak dalam penelitian ini digunakan parameter pada tabel 3 berikut. 
Jurnal TEKNO

(Civil Engineeering, Elektrical Engineeering and Industrial Engineering)

Vol. 17, No : 2, Oktober 2020, p-ISSN:1907-5243, e-ISSN: 2655-8416

Tabel 4 Parameter Karakteristik DAS

\begin{tabular}{|l|c|}
\hline \multicolumn{1}{|c|}{ Karakteristik DAS } & Parameter \\
\hline Catchment area, A $\left(\mathrm{km}^{2}\right)$ & 29 \\
Main river length, L (km) & 17,2 \\
Mean river slope, S (-) & 0,05 \\
Drainage density, D (km/ $\left.\mathrm{km}^{2}\right)$ & 2,14 \\
Relative upstrean area, RUA (-) & 0,57 \\
Width factor, WF (-) & 1,69 \\
Symmetry factor, SIM (-) & 0,96 \\
Source factor, SF (-) & 0,36 \\
Source frequency, SN (-) & 0,51 \\
Joint frequency, JN (-) & 25 \\
\hline
\end{tabular}

1) HS Gama I

Perhitungan analisis hidrograf satuan Gama I untuk DAS Sekanak dalam penelitian ini digunakan parameter pada tabel 6 berdasarkan perhitungan.

Tabel 5 Parameter HS Gama I

\begin{tabular}{|l|c|}
\hline \multicolumn{1}{|c|}{ Parameter HSS GAMA 1 } & Nilai \\
\hline TR $($ jam $)$ & 2,00 \\
Qp $\left(\mathrm{m}_{3} / \mathrm{s}\right)$ & 2,17 \\
TB $($ jam $)$ & 21,50 \\
K (jam) & 5,00 \\
Debit Baseflow; Qb (m3/s) & 8,53 \\
Phi Indeks ; $\phi(\mathrm{mm} /$ jam) & 10,49 \\
\hline
\end{tabular}

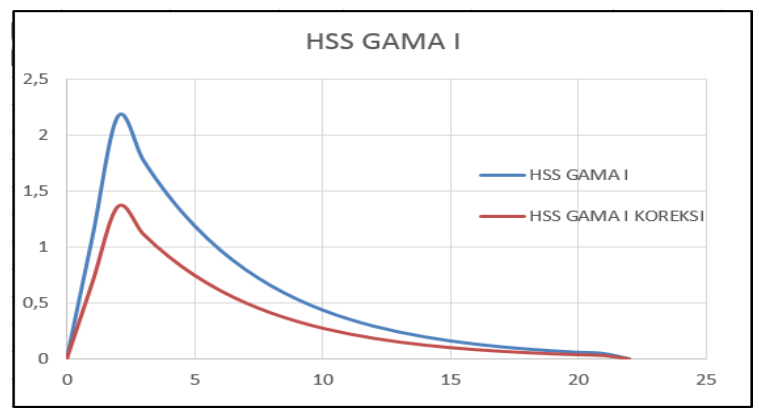

Gambar 9 Grafik Hidrograf Satuan Sintetik Gama I 
(Civil Engineeering, Elektrical Engineeering and Industrial Engineering)

Vol. 17, No : 2, Oktober 2020 , p-ISSN:1907-5243, e-ISSN: 2655-8416

\section{2) HS Nakayasu}

Perhitungan analisis hidrograf satuan Nakayasu untuk DAS Sekanak dalam penelitian ini digunakan parameter pada tabel 7 berdasarkan perhitungan.

Tabel 6 Parameter HS Nakayasu

\begin{tabular}{|l|c|}
\hline Parameter HSS NAKAYASU & Nilai \\
\hline $\operatorname{Tg}($ jam $)$ & 1,40 \\
$\operatorname{Tr}($ jam$)$ & 0,70 \\
$\alpha$ & 2,00 \\
$\mathrm{~T}_{0,3}($ jam $)$ & 2,80 \\
$\operatorname{Tp}($ jam) & 2,20 \\
$\mathrm{Qp}\left(\mathrm{m}_{3} / \mathrm{s}\right)$ & 2,33 \\
$0,3 \mathrm{Qp}$ & 0,700 \\
$0,09 \mathrm{Qp}$ & 0,210 \\
\hline
\end{tabular}

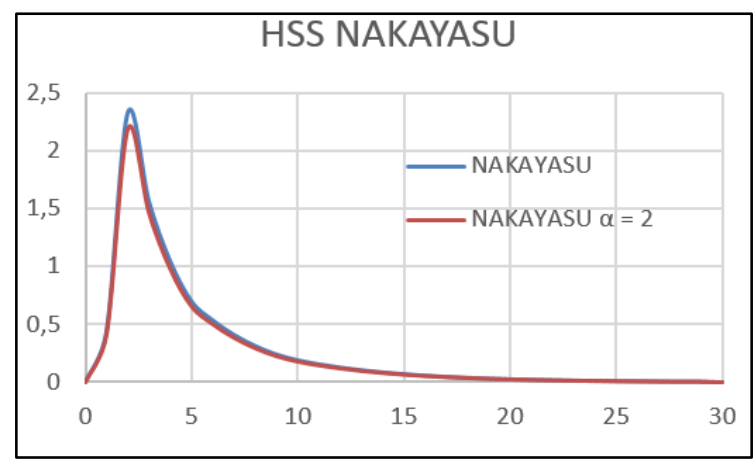

Gambar 10 Grafik Hidrograf Satuan Sintetik Nakayasu

3) HS SCS

Perhitungan analisis hidrograf satuan SCS untuk DAS Sekanak dalam penelitian ini digunakan parameter berdasarkan perhitungan.

Waktu Konsentrasi; Tc (jam) $\quad 1,878$

$\mathrm{T}_{\text {lag }} \quad 1,13$

Tp 1,63

Debit Puncak; Qp $\left(\mathrm{m}^{3} / \mathrm{s}\right) \quad 4,95$ 


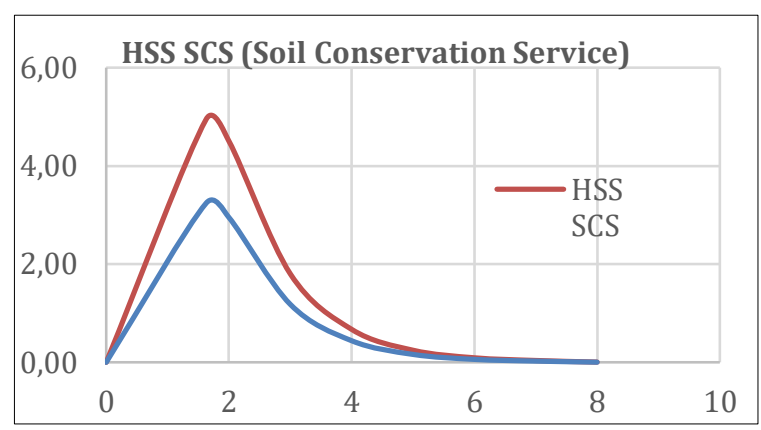

Gambar 11 Grafik Hidrograf Satuan Sintetik SCS

4) Perbandingan Hidrograf

Perhitungan analisis hidrograf dianalisis dengan membandingkan Hidrograf Satuan Sintetik untuk Gama I, Nakayasu ( $\alpha=1,5,2$ dan 3) dan SCS dengan HSS Terukur seperti yang ditampilkan dalam gambar 9 .

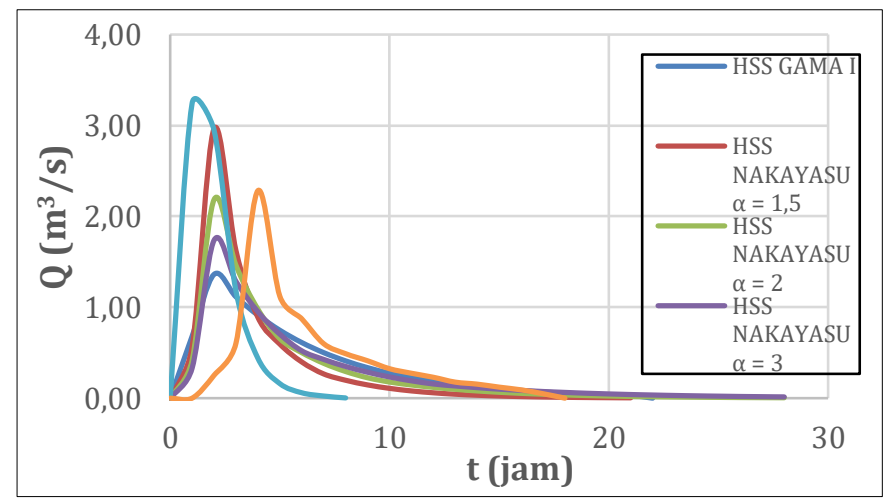

Gambar 12 Grafik Hidrograf Perbandingan HSS dengan HS Terukur

5) Penyimpangan antar Hidrograf Satuan Sintetik

Besar penyimpangan yang terjadi antara HSS Gama I, Nakayasu dan SCS terhadap HSS terukur terlihat di tabel 8. 


\section{Jurnal TEKNO}

(Civil Engineeering, Elektrical Engineeering and Industrial Engineering)

Vol. 17, No : 2, Oktober 2020 , p-ISSN:1907-5243, e-ISSN: 2655-8416

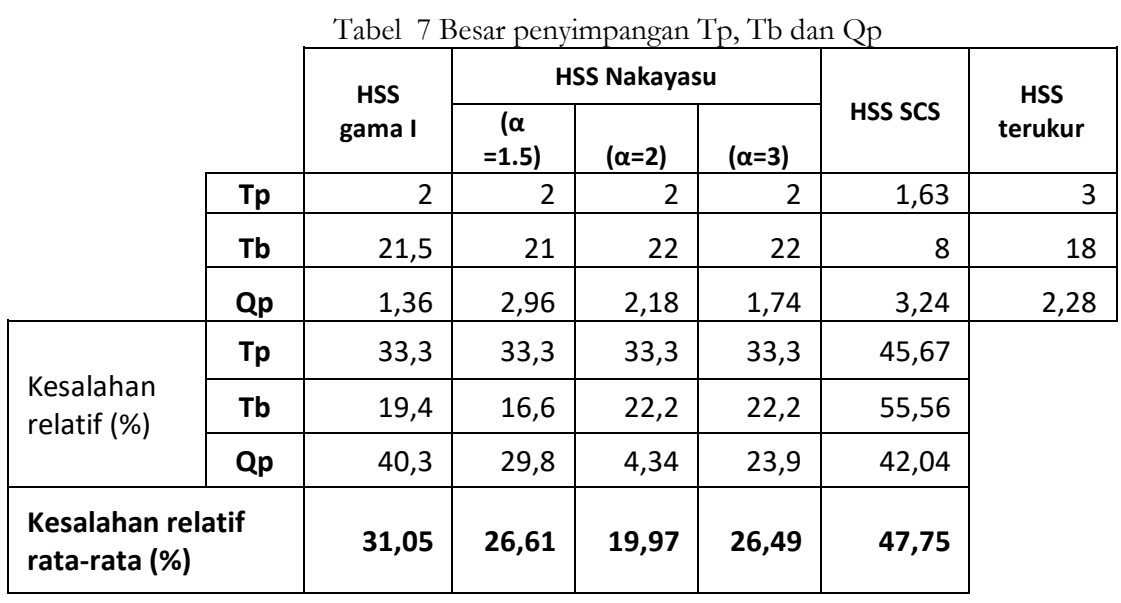

\section{KESIMPULAN}

Berdasarkan penelitian analisis hidrograf satuan pada DAS Sekanak dengan menggunakan metode HS Gama 1, Nakayasu dan SCS maka dapat dilihat bahwa waktu puncak (Tp) dari HSS Gama I, Nakayasu dan SCS cenderung lebih cepat dari HS terukur dengan metode Collins. Terjadi penyimpangan debit puncak (Qp) yang cukup besar dari HSS SCS terhadap HS terukur, yaitu sebesar 42,04\% dan kesalahan relatif rata-rata sebesar $47,75 \%$.

Dari hasil perbandingan Tb, Tp dan QP dapat dilihat bahwa penyimpangan paling kecil dari kesalahan relatif rata-rata antara HSS Gama I, Nakayasu dan SCS terhadap HS terukur dengan metode Collins adalah HSS Nakayasu $\alpha=2$ sebesar 19,97\%. Oleh karena itu metode HSS Nakayasu dianggap mewakili analisa hidrograf satuan di DAS Sekanak.

\section{DAFTAR PUSTAKA}

[1] Hermance, J., "Environmental Geophysiscs/Hydrology". Diambil kembali dari http://www.geo.brown.edu/research/Hydrology/FTP_site_5099-05/ geol0580_02_WatershedDelineation_158_2009_(handouts).pdf, 2013.

[2] A Syarifudin, "Hidrologi Terapan”, Beta Offset, Yogyakarta, 2018

[3] Sri Harto, “Analisis Hidrologi”, Jakarta: Gramedia Pustaka Utama, 1993.

[4] A Syarifudin, "Drainase Perkotaan Berwawasan Lingkungan”, Beta Offset Yogyakarta, 2018

[5] Suripin. “Sistem Drainase Perkotaan yang Berkelanjutan”, Yogyakarta: Andi Offset, 2002

[6] Jayadi, R., “Hidrologi I, Pengenalan Hidrologi”, Yogyakarta: UGM Press, 2000.

[7] Kodoatie, R., \& Sugiyanto, "Banjir, Beberapa Penyebab dan Metode Pengendaliannya dalam Perspektif Lingkungan”, Yogyakarta: Pustaka Belajar, 2003.

[8] Sherman, L., "Streamflow from rainfall by the unit hydrograf method",. England: News-Record, 1932.

[9] Soemarto, “Hidrologi Teknik”, Surabaya: Usaha Nasional, 1987.

[10] Triatmodjo, B., “Hidrologi Terapan”, Yogyakarta: Beta Offset. 2008. 